\title{
Sexually transmitted infections in adolescent girls
}

\author{
F M MULCAHY AND C J N LACEY \\ From the Department of Genitourinary Medicine, General Infirmary, Leeds
}

SUMMARY Two hundred and ten adolescent girls in residential care with an age range of 12 to 16 years were screened for sexually transmitted infections. The incidences of infection with Neisseria gonorrhoeae, Chlamydia trachomatis, and Trichomonas vaginalis were $13 \cdot 7 \%, 16 \cdot 2 \%$, and 16.0\% respectively. Pelvic inflammatory disease was identified in $16.4 \%$ of those with $C$ trachomatis or gonococcal infection. The high morbidity from sexually transmitted disease in these adolescent girls reinforces the need for screening similar at risk teenagers.

\section{Introduction}

Sexually transmitted diseases (STDs) occur commonly in sexually active young women. The incidence of individual STDs in adolescent girls attending an STD clinic in London was described by Forster et al. ${ }^{1}$ They showed that in girls aged 15-19 the incidence of syphilis, gonorrhoea, infection with Trichomonas vaginalis, herpes simplex virus, and genital warts remained almost unchanged in the period 1972-82. Similar studies from the United States of America have shown that in this age group there is a high incidence of infection with Chlamydia trachomatis as well. ${ }^{23}$

Since 1966 Leeds City Council has provided an observation and assessment centre for young teenage girls. The centre provides 20 places for girls aged up to 16 from the Yorkshire region who have committed offences and are awaiting legal proceedings at a court of law. It is particularly concerned with girls with identified behavioural problems who have been engaged in prostitution or who have been sexually abused. Girls are also admitted when made subject to an interim care order relating to irregular attendance at school. Screening for sexually transmitted infection is undertaken where appropriate as part of a general assessment.

We here report the prevalence of sexually transmitted infection in young girls in residential care in Leeds in 1978-85.

\section{Patients and methods}

We screened 210 adolescent girls for STD between January 1978 and December 1985. Their mean age

Address for reprints: Dr F. M. Mulcahy, Department of Genitourinary Medicine, The General Infirmary at Leeds, Great George Street, Leeds LS1 3EX

Accepted for publication 31 May 1986 was $14 \cdot 1$ (range 12 to 16 ) years. Of the 210 girls, 187 (89\%) were white, eight $(4 \%)$ were black (West Indian), three (1\%) were Asian, and $12(6 \%)$ were of mixed ethnic origin. The girls were self referred after being counselled by the residential staff of the assessment centre. Each girl was interviewed and examined by a visiting genitourinary physician. A previous admission into residential care with screening for STD did not preclude further investigation. A new presentation of each patient who attended more than once was reported as a separate diagnosis. A detailed genitourinary and sexual history was obtained.

Each patient underwent a full pelvic examination, during which clinical findings were recorded. Routine investigations comprised microscopy of urethral, cervical, and vaginal specimens, cultures for Neisseria gonorrhoeae from the urethra and cervix, and culture for $T$ vaginalis from the vagina. Standard methods of specimen collection, culture techniques, and diagnostic criteria have been described. ${ }^{4}$ This analysis is of 210 girls; in the second half of the study period (from 1981) specimens for culture for $C$ trachomatis were also collected from 134 girls. A cotton wool swab was rotated in the cervical canal and broken off into a bijou bottle containing $0.2 \mathrm{~mol} / \mathrm{l}$ sucrose phosphate transport medium. This was kept at $4^{\circ} \mathrm{C}$ until inoculated on to chlorheximide treated McCoy cells. Cell monolayers were stained with Giemsa, and were examined for typical inclusions after being incubated for 48 hours. In patients with genital ulceration, exudate from the base of the ulcers was collected on a cotton wool swab and placed in virus transport medium until inoculated on to confluent monolayers of human embryo fibroblasts, which were incubated at $37^{\circ} \mathrm{C}$ for up to 14 days and observed daily for the characteristic cytopathic effect of herpes simplex virus. Serological testing for syphilis was performed in all cases. 
TABLE I Sexual histories of 210 adolescent girls in residential care screened for sexually transmitted diseases

\begin{tabular}{lc}
\hline Sexual history & No (\%) of girls \\
\hline Had engaged in prostitution & $47(22 \cdot 4)$ \\
Sexually abused & $7(3 \cdot 3)$ \\
Regular (more than 4 weeks' duration) & $74(35 \cdot 2)$ \\
$\quad$ sexual partner & \\
Two or more sexual partners within & $66(31 \cdot 4)$ \\
$\quad$ preceeding four weeks & $16(7 \cdot 6)$ \\
Denied having had sexual intercourse & \\
\hline
\end{tabular}

\section{Results}

There were 307 new presentations of 210 girls screened for STD, many of the girls having repeated admissions for separate offences. Of the 210 girls, 47 openly admitted to having engaged in prostitution. Seven had been sexually abused (three had been raped and four had been exposed to incest from the ages of 5 to 8 years). These sexual histories are summarised in table I.

TABLE II Pattern of sexually transmitted disease (STD) in 210 adolescent girls in residential care

\begin{tabular}{lc}
\hline No of episodes of STD & No of girls \\
\hline 0 & 132 \\
1 & 35 \\
2 & 25 \\
3 & 11 \\
4 or more & 7 \\
\hline
\end{tabular}

Table II shows that 132 of the 210 girls screened had no evidence of STD. The remaining 78 girls presented 175 times, with seven girls having four or more infections, 11 having three infections, and 25 having two infections with sexually transmitted pathogens. The prevalence of $N$ gonorrhoeae, $T$ vaginalis, $C$ trachomatis, herpes simplex viral infection, and genital warts is shown in table III. In 307 new presentations of 210 girls screened between January 1979 and December 1985, 42 infections with $N$ gonorrhoeae (13.7\%) and 49 infections with $T$ vaginalis $(16 \%)$ were diagnosed. $C$ trachomatis was isolated from cervical cultures in 32 of 198
TABLE III Prevalence of sexually transmitted disease (STD) in adolescent girls

\begin{tabular}{lcl}
\hline Infective organism & No of presentations & No $\%$ of episodes \\
\hline Neisseria gonorrhoeae & 307 & $42(13 \cdot 7)$ \\
Trichomonas vaginalis & 307 & $49(16)$ \\
Chlamydia trachomatis & 198 & $32(16 \cdot 2)$ \\
Genital wart virus & 307 & $12(3 \cdot 9)$ \\
Herpes simplex virus & 307 & $4(1 \cdot 3)$ \\
\hline
\end{tabular}

presentations $(16 \cdot 2 \%)$ screened during the later period January 1981 to December 1985. N gonorrhoeae and $C$ trachomatis were isolated together in seven of these cases. We arbitrarily divided our results into three periods, 1978-80, 1981-3, and 1984-5 for further analysis (table IV). Though we recognised that significant changes in incidence cannot be concluded from this data, the trend suggests that $C$ trachomatis and $T$ vaginalis are increasingly important pathogens in sexually active adolescents in residential care.

Herpes genitalis and genital warts were diagnosed on four and 12 occasions respectively. It is noteworthy that cervical cytology in two girls with genital warts showed dysplasia when the girls were seen at Leeds General Infirmary two years later. The other 10 girls were lost to follow up after discharge from the assessment centre.

Two girls had pediculosis pubis and four had scabies. The prevalence of these infestations is undoubtedly an underestimate. Because of the risk of spreading parasitic infections in an institution, all symptomatic girls are disinfested on admission to the centre, before a definitive diagnosis can be made by the visiting doctor.

Pelvic inflammatory disease was diagnosed clinically on the basis of pyrexia, abdominal pain, vaginal discharge, pain on cervical excitation, and adnexal tenderness on bimanual examination in 16 girls, of whom five yielded $C$ trachomatis on cervical culture and six yielded $N$ gonorrhoeae from the urethra and cervix. One girl aged 13 years had a gonococcal Bartholin's abscess that required surgical intervention.

Syphilis serology test results were negative in all cases.

TABLE IV Prevalence of sexually transmitted disease (STD) in adolescent girls during three periods

No infected (\% presented) in:

\begin{tabular}{llll} 
Infective organism & $\begin{array}{l}1978-80 \\
(109 \text { presented })\end{array}$ & $\begin{array}{l}1981-3 \\
(115 \text { presented })\end{array}$ & $\begin{array}{l}1984-5 \\
(83 \text { presented })\end{array}$ \\
\hline Neisseria gonorrhoeae & $19(17 \cdot 4)$ & $16(13 \cdot 9)$ & $7(8 \cdot 4)$ \\
Chlamydia trachomatis & $\mathrm{ND}$ & $11(9 \cdot 6)$ & $21(25 \cdot 3)$ \\
Trichomonas vaginalis & $11(10 \cdot 1)$ & $17(14 \cdot 8)$ & $19(22 \cdot 9)$ \\
\hline
\end{tabular}

$\mathrm{ND}=$ Not done 
Discussion

Adolescents are engaging in sexual intercourse at an earlier age, and often with multiple partners. This emerges from a background of increased urbanisation, changing sexual mores, and an earlier age of menarche. ${ }^{56}$ Screening adolescents for sexually transmitted infections is now routine in many health care settings in the United States of America. The results of this study confirm that $C$ trachomatis, $N$ gonorrhoeae, and $T$ vaginalis can often be indentified in sexually active girls aged under 16 in residential care in the United Kingdom.

Our study population clearly showed several risk factors for STD: early age at first intercourse, low socioeconomic background, history of sexual abuse, and a $23 \cdot 3 \%(47 / 210)$ prevalence of prostitution in girls aged 12 to 16 . In contrast to North American study groups, which contained mainly black girls, $89 \%$ of our girls were white.

In a study of delinquent girls in Scotland during the 1960 s, $N$ gonorrhoeae was isolated in $1.8 \%$ and $T$ vaginalis in $23.6 \%$ of 110 girls screened. ${ }^{7}$ In the study published here $N$ gonorrhoeae was isolated on 42 occasions (13.7\% of presentations). A prevalence rate as high as this has only been seen otherwise in an STD clinic. The overall prevalence rate for $C$ trachomatis was comparable with those found in women attending STD clinics $^{8}$ and in adolescents attending obstetric clinics. ${ }^{9}$ In the later period, 1984-5, the incidence of infection with $C$ trachomatis ( $25 \cdot 3 \%$ of presentations) and $T$ vaginalis $(22.9 \%)$ indicated that infections with these pathogens may be increasingly important in adolescent girls in care. The implications are clearly shown. It is interesting that a core group of 78 girls contributed all the positive results.

Recent trends for pelvic inflammatory disease in the United Kingdom have shown age specific rates increasing in the 15 to 19 and 20 to 24 year old age groups. ${ }^{10}$ The risk of acquiring salpingitis of a sexually active 15 year old girl in Sweden has been calculated to be 1:8 and of girls aged 16 years $1: 10 .{ }^{11}$ These workers showed an appreciable decrease in the incidence of pelvic inflammatory disease with increasing age in sexually active women. They also estimated that one out of four women with pelvic inflammatory disease would suffer from one or more episodes of chronic abdominal pain, infertility, or ectopic pregnancy. Of the 210 girls in our study, 16 had a clinically diagnosed pelvic inflammatory disease at presentation. More importantly, $16.4 \%$ of girls infected on presentation with $N$ gonorrhoeae or $C$ trachomatis, or both, had pelvic inflammatory disease. This high morbidity from sexually transmitted infections in such a young age group is a matter of considerable concern.

Cervical intraepithelial neoplasia has been strongly linked with papillomavirus infection. ${ }^{12}$ One study estimated that the prevalence rate for early neoplastic changes on cervical cytology was $35 / 1000$ in sexually active adolescent girls aged 12 to 16 who were in a youth detention centre in New York City. ${ }^{13}$ In Leeds 12 of 210 girls had papillomavirus infection, and we know that two of them had cervical dysplasia two years later. This indicates that routine cytological screening of sexually active adolescents in care in the United Kingdom should also be instituted.

We have identified young girls in residential care in Leeds as being a major risk group for sexually transmitted infections. Probably none of the girls screened would have sought specific care or advice for STD outside an institutional setting. In view of the high morbidity from sexually transmitted infections, in particular pelvic inflammatory disease, it is important to investigate and treat similar teenagers at risk throughout the United Kingdom.

We thank Dr M A Waugh for encouragement and advice.

\section{References}

1. Forster GE, Robinson GE, Munday PE. Sexually transmitted diseases: an epidemic in adolescent girls? British Journal of Venereal Diseases 1984;60:402-5.

2. Saltz GR, Linnemann CC, Brookman RL, Rautl JL. Chlamydia trachomatis cervical infection in female adolescents. J Pediatr 1981;98:981-5.

3. Fraser JJ, Rettig PJ, Kaplan DW. Prevalence of cervical Chlamydia trachomatis and Neisseria gonorrhoeae in female adolescents. Paediatrics 1983;71:333-6.

4. Nayyar KC, O'Neill JJ, Waugh MA. Isolation of Chlamydia trachomatis from women attending a clinic for sexually transmitted disease. British Journal of Venereal Diseases 1976;52:396-8.

5. Tanner JM. Foetus into man: heredity and environment in the control of growth. Cambridge, Massachusetts: Harvard University, 1978:143, 145, 153.

6. Zelnik M, Kartner JF. Sexual activity, contraceptive use and pregnancy among metropolitan teenagers 1971-1979. Fam Plann Perspect 1980;12:230-7.

7. Robertson DHH, George G. Medical and legal problems in the treatment of delinquent girls in Scotland. British Journal of Venereal Diseases 1970;46:46-53.

8. Kinghorn GR, Waugh MA. Oral contraceptive use and prevalence of infection with Chlamydia trachomatis in women. British Journal of Venereal Diseases 1981;57:87-90.

9. Hardy PH, Hardy JB, Nell EE, Graham DA, Spence MR, Rosenbaum RC. Prevalence of six sexually transmitted disease agents among pregnant inner-city adolescents and pregnancy outcome. Lancet 1984;ii:333-7.

10. Adler MW. Trends for gonorrhea and pelvic inflammatory disease in England and $W$ ales and for gonorrhea in a defined population. Am J Obstet Gynecol 1980;138:901-4.

11. Weström $\mathbf{L}$.Incidence, prevalence and trends of acute pelvic inflammatory disease and its consequences in industrialized countries Am J Obstet Gynecol 1980;138:880-92.

12. McCance DJ Campion MJ, Clarkson PK, et al. Prevalence of human papillomvirus type 16 DNA sequences in cervical intraepithelial neoplasia and invasive carcinoma of the cervix Br J Obstet Gynaecol 1985;92:1101-5.

13. Hein K, Scheiber K, Cohen MI Koss LG. Cervical cytology : the need for routine screening in the sexually active adolescent. J Pediatr 1977;91:123-6. 